\title{
Aguas medicinales y culto a las aguas en Extremadura
}

\author{
V. RODRIGO * \\ S. HABA*
}

\section{INTRODUCCIÓN}

Al hablar del tema de las aguas mineromedicinales en Extremadura vinculadas a aspectos religiosos o de culto antiguos resulta de cierto interés considerar, aunque sea brevemente, el tratamiento bibliográfico que esta materia ha recibido en la región y los diversos estudios que ha suscitado, hasta fechas recientes, por parte de los investigadores.

Existe, por una parte, un variado conjunto de obras, procedentes de eruditos locales y recopiladores que nos dan a conocer algunas fuentes y manantiales mineromedicinales, relacionados ya con el hecho religioso, bien romano o de época cristiana. Podemos citar, entre estas obras, como generales, las de Ponz y Madoz ${ }^{1}$ y, en el ámbito regional, las de Pesado Blanco ${ }^{2}$, sobre Fuente Santa de Galisteo (Cáceres), Diaz y Pérez y Escobar Prieto ${ }^{3}$, sobre Baños de Montemayor, Mélida ${ }^{4}$ y las noticias de Sayans ${ }^{5}$ para la zona de Plasencia.

Otro grupo de autores abordan el tema desde una perspectiva arqueológica, estableciendo vínculos claros con el mundo romano, ya desde

* Universidad de Extremadura.

Ponz, A., Viage de España. Madrid 1784, libros VII y VIII; Madoz, P., Diccionario geográfico-estadístico-histórico de España y sus posesiones de Ultramar. Cáceres 1955.

2 Pesado Blanco, S., "Las termas de Montemayor», Revista de Extremadura, IV, 1902, págs. 263-270; Escobar Prieto, E., «Galisteo», Revista de Extremadura, VIII, 1906, págs. 74 ss.

${ }^{3}$ Diaz y Pérez, N., Baños de Baños. Madrid 1880

${ }^{4}$ Melida, J. R., Catálogo Monumental de España. Provincia de Cáceres. Madrid 1914-16.

${ }^{5}$ Sayans, M., Artes y pueblos primitivos de la Alta Extremadura. Plasencia 1957. 
principios de siglo, como Paredes Guillén ${ }^{6}$; importantes son, asimismo, los artículos de Álvarez Martínez sobre el balneario de Alange ${ }^{7}$ e incluso la excavación de unas termas romanas ${ }^{8}$, con resultados publicados y que parece mostrar también esa relación de culto.

Más concretamente, varios trabajos específicos se han centrado en las inscripciones dedicadas a las divinidades acuáticas y su vinculación con aguas de carácter terapéutico. Fundamental, desde luego, fue el de Roldán Hervás ${ }^{9}$ sobre las lápidas de Baños de Montemayor. A él han seguido los de Callejo ${ }^{10}$, Melena ${ }^{11}$, Herrera y Gil Montes ${ }^{12}$, Redondo Rodriguez ${ }^{13}$, Domínguez Moreno y Paniagua ${ }^{14}$ y Río-Miranda ${ }^{15}$.

Por último, merecen nombrarse aquí como fuente bibliográfica las Memorias de diferentes médicos interesados en el tema, por los datos que aportan a nuestro estudio ${ }^{16}$.

- Paredes Guillén, V., “Inscripciones del Villar de Plasencia y situación de Caecilius Vícus", Revista de Extremadura, Xl, 1909, págs. 260-269.

'Alvarez Martinfz, J. M., "Alange y sus termas romanas", Revista de Estudios Extremeños, XXIX, III. Badajoz 1973; «Alange y sus termas romanas", Alminar, 11, enero 1980, págs. $16-17$.

${ }^{8}$ Calero Carretero, J. A., y Membrillo, l., "Las termas de La Nava", Alminar, 35, 1982, págs. 14-15.

9 Roldán Hervas, J. M., "Las lápidas votivas de Baños de Montemayor", Zephyrus, XVI, 1965, págs. 23 ss.

10 Callejo Serrano, C., «Cédulas epigráficas del campo norbense», Zephyrus, XVIII, 1967, págs. 85 ss.

11 MelenA, J. L., «Un ara votiva romana en El Gaitán (Cáceres)», Veleia, 1. Vitoria 1984, págs. 233-259.

12 Herrera, G., y Gil Montes, J., "Un ara votiva relacionada con el culto a las aguas y el puente de Alcántara", Cuadernos de Grado Medio, 2, I. B. El Brocense. Cáceres 1984, págs. $37-41$.

13 Redondo Rodriguez, J. A., «La religión grecorromana en el sureste cacereño a través de sus testimonios epigráficos", Manifestaciones Religiosas en Lusitania. Cáceres, Universidad de Extremadura, 1986, págs. 15-29.

${ }^{14}$ Dominguez Moreno, J. M., y Paniagua, M., "Aportación al estudio de la religión primitiva en Ahigal», Boletín Amigos de Ahigal, 7, febrero 1981.

${ }^{15}$ Rio-MiRAnda, J., «Epigrafia romana inédita", Boletin del Grupo Cultural de Valdeobispo 1 , enero 1981

${ }^{16}$ Martinez Serrano, F., Investigaciones hidrológicas... sobre el manantial termal... de Baños de Montemayor y Béjar. Plasencia 1842-43; Rodríguez Solano, C., Virtudes medicinales y análisis del agua mineromedicinal de Baños. Cáceres 1850; Crespo y EsconiazA, B. Breve reseña de las aguas sulfurado-sódicas termales de Montemayor o Baños. Béjar 1889; Maraver Eyzaguirre, F., Tesis doctoral inédita sobre Baños de Montemayor. Madrid, Universidad Complutense, 1986; Álvarez Taladriz, L., Memoria histórico-científica de las aguas sulfurosas frias de la fuente de El Salugral en Hervás. Béjar 1879; Rodriguez PiniLLA, H., Memoria histórico-clínica de las aguas minerales de Valdelazura. Plasencia 1910; VILLAESCUSA, J., Monografia de las aguas y Baños de Alange. Madrid 1850; BERBEN, A., Aguas bicarbonatadas-cálcicas de Alange. Madrid 1895. 
Cuando, hacia 1986, comenzamos a adentrarnos en el mundo del culto a las fuentes-manantiales mineromedicinales, desde nuestra posición de arqueólogas e historiadoras, nos planteamos hacerlo desde una perspectiva global y atendiendo a las diferentes variables que concurren en el tema.

Se imponía, en principio, una labor de catalogación, clasificación y plasmación cartográfica de todos aquellos lugares con aguas de características terapéuticas. Se tomó como base una ficha modelo donde reflejar los datos, que se obtuvieron tanto de noticias escritas como, fundamentalmente, de la transmisión oral y el trabajo de campo.

Como fruto de ello observamos que, en nuestro mapa regional (fig. 1), se han multiplicado los lugares hasta ahora documentados, pero, además, constantemente se acrecientan.

Teniendo como base esta información que supera, por el momento, el centenar de lugares, hemos realizado una sistematización que ha permitido no sólo categorizar los diversos enclaves, sino ponerlos en relación con factores que son objeto de nuestro estudio, como su mayor o menor densidad, en relación con el subsuelo y las condiciones geológicas; fenómenos de distribución, en conexión con asentamientos antiguos y vías de comunicación; de gran interés es también el factor toponímico, y, por último, el hecho religioso y de culto. Éste, que para la época romana se refleja sobre todo en restos constructivos y epigráficos, muestra múltiples elementos de pervivencia en nuestra zona de estudio que quedan patentes en la religión cristiana.

\section{LAS FUENTES MINEROMEDICINALES Y LAS VIAS NATURALES DE COMUNICACIÓN}

Sin duda, uno de los principales factores de distribución de los manantiales mineromedicinales es la composición del subsuelo y la estructura geológica de la zona. Pues, en efecto, sabemos que el manantial necesita unas condiciones de temperatura interior para cargarse de componentes y unas adecuadas zonas de fracturas o fallas del terreno para su surgencia.

En la zona Norte de la provincia de Cáceres hemos estudiado una interesante área (fig. 2) donde se conjugan un hecho geológico, la falla Ávila-San Vicente, con la existencia de una fundamental vía de comunicación, vigente desde tiempos protohistóricos, al menos: la Vía de la Plata. 


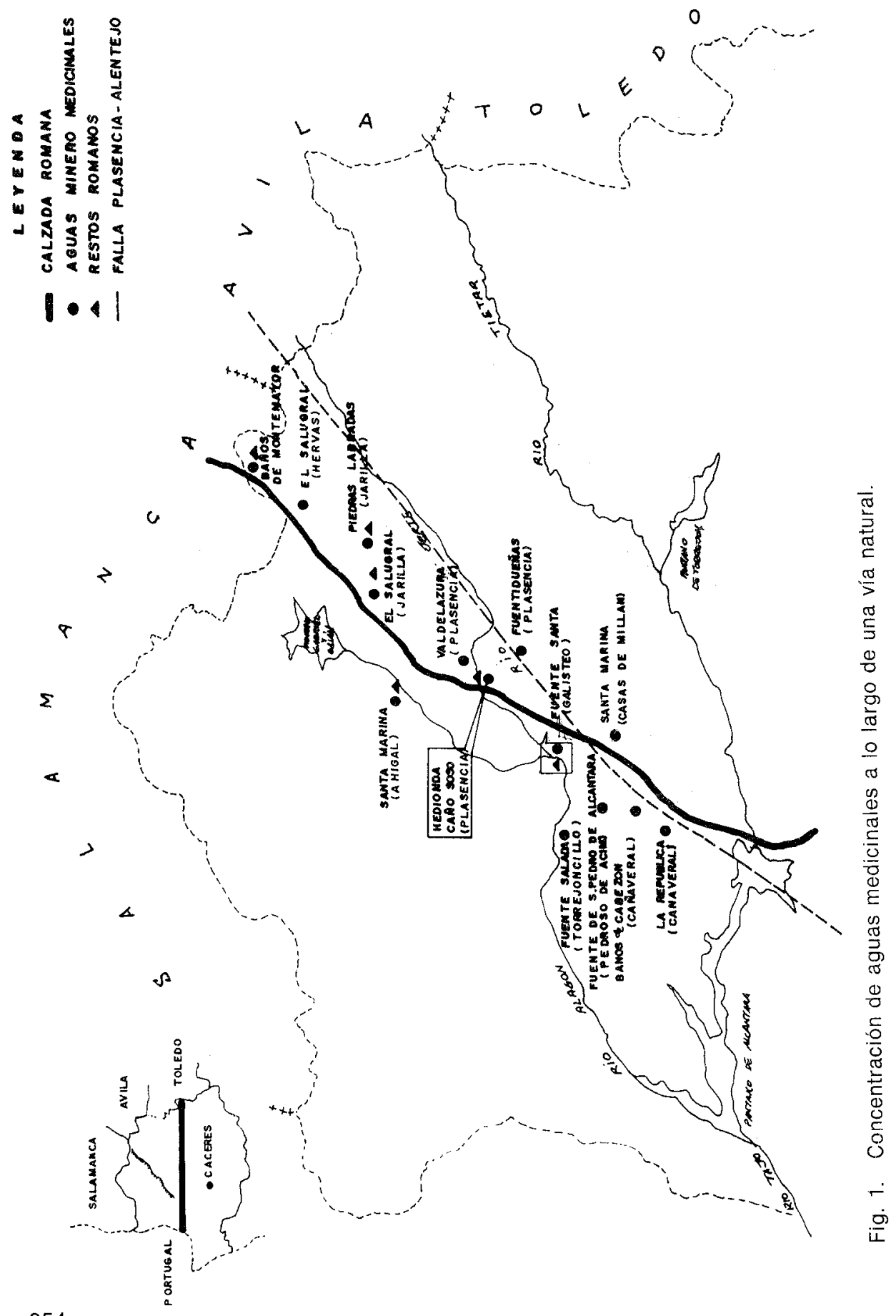




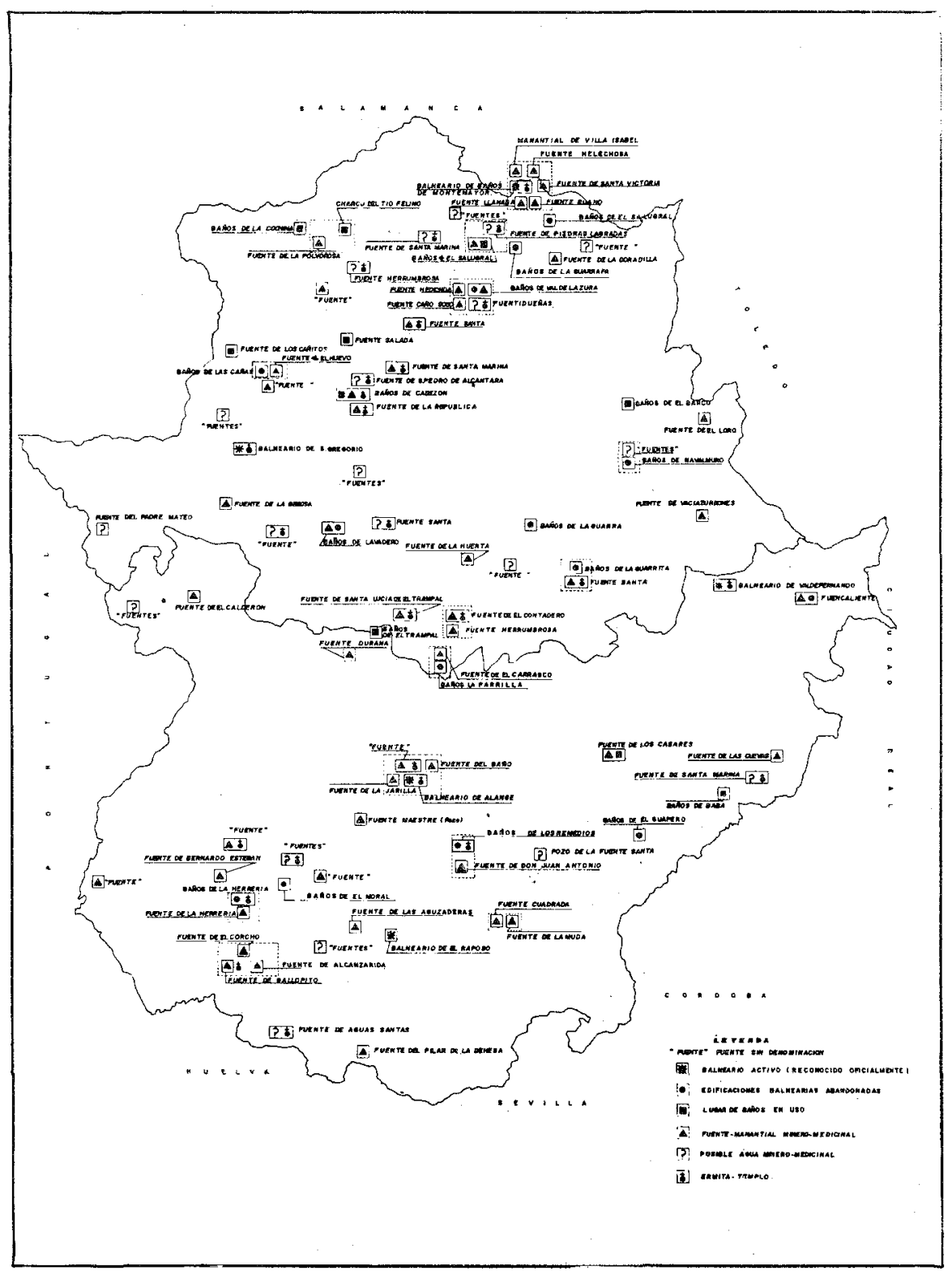

Fig. 2. Extremadura. Clasificación de lugares de aguas minero-medicinales. 
Este estrecho pasillo, entre dos fosas de sedimentación, fue aprovechado por los pueblos aquí asentados y se utilizó como vía natural desde época tartésica ${ }^{17}$. Posteriormente fue vía de penetración militar, en época romana, dando lugar a la Calzada que, más tarde, fue conocida como Via de la Plata.

Sin detenernos en los numerosos yacimientos prehistóricos que aquí existen (Boquique, Berrocalillo, El Butracón...), debemos señalar el auge que alcanzó la zona en época romana, con la creación del municipio caparense (Cáparra), y como lo corroboran los asentamientos rurales localizados en el territorio de esta ciudad. La máxima concentración del poblamiento de este área se dispone a lo largo de la calzada. Al mismo tiempo, un buen número de balnearios y fuentes medicinales, en general, se alinean en sus proximidades. Algunos de estos lugares tienen cierta entidad fuera de la región, pero la mayoría resultan desconocidos. Destaquemos algunos datos referidos a cada uno de ellos, en dirección NorteSur.

Baños de Montemayor.-El más importante balneario de la zona que estudiamos es un centro termal plenamente vigente en nuestros días. Goza de una excelente posición geográfica, con el puerto de Baños-Béjar y bien comunicado desde la antigüedad, ya que la atraviesa la Vía de la Plata, constituyendo una de sus paradas, Caecilius Vicus.

Sobre él existe una abundante bibliografía, tanto desde el punto de vista médico como histórico. El edificio actual de los baños es una construcción del siglo xIX cuya parte más antigua es una piscina en cuyo interior se aprecian vestigios de un muro romano de considerables dimensiones. En las sucesivas obras de remodelación que este centro sufrió durante todo el $x_{1} x$ se hallaron diversos restos arqueológicos (muros, monedas, inscripciones, estatuillas, etc.), que conocemos por las Memorias de las médicos Directores del balneario y por eruditos e historiadores. Según testimonio de Limón Montero ${ }^{18}$, a finales del XVII las edificaciones romanas ya habian desaparecido y sólo quedaba una charca con pilón. Sus aguas fueron recogidas en una arqueta que se cubrió con bóveda, a instancias del obispo de Coria, don Juan Porras Atienza, con lo que comenzó el nuevo periodo histórico de este centro.

Sus aguas ya fueron veneradas por los romanos, lo que queda patente, sobre todo, en los abundantes epígrafes votivos exhumados en las

\footnotetext{
17 GiL Montes, J., «La ruta natural más antigua de Extremadura», Cuadernos de Grado Medio, núm. 1, I. B. El Brocense. Cáceres 1983, págs. 491-492.

${ }^{18}$ Limón Montero, A., Espejo cristalino de las aguas de España. Madrid 1697.
} 
obras de acondicionamiento ya señaladas durante el siglo pasado. Conocemos un total de 21 lápidas, de las que 14 están dedicadas a las Nimphae (lám. l) con o sin epíteto de caparenses, dos se dedican a Fontana, dos a Salus (lám. II) y tres que resultan ilegibles o dificiles de interpretar. El contenido de estos epígrafes nos es conocido a través de las fuentes bibliográficas, sobre todo el CIL II $(883,884,885,886,887,888,889,890$, $891,892)$ y Fita y Colomé ${ }^{19}$. En 1965 fue publicado un estudio crítico de

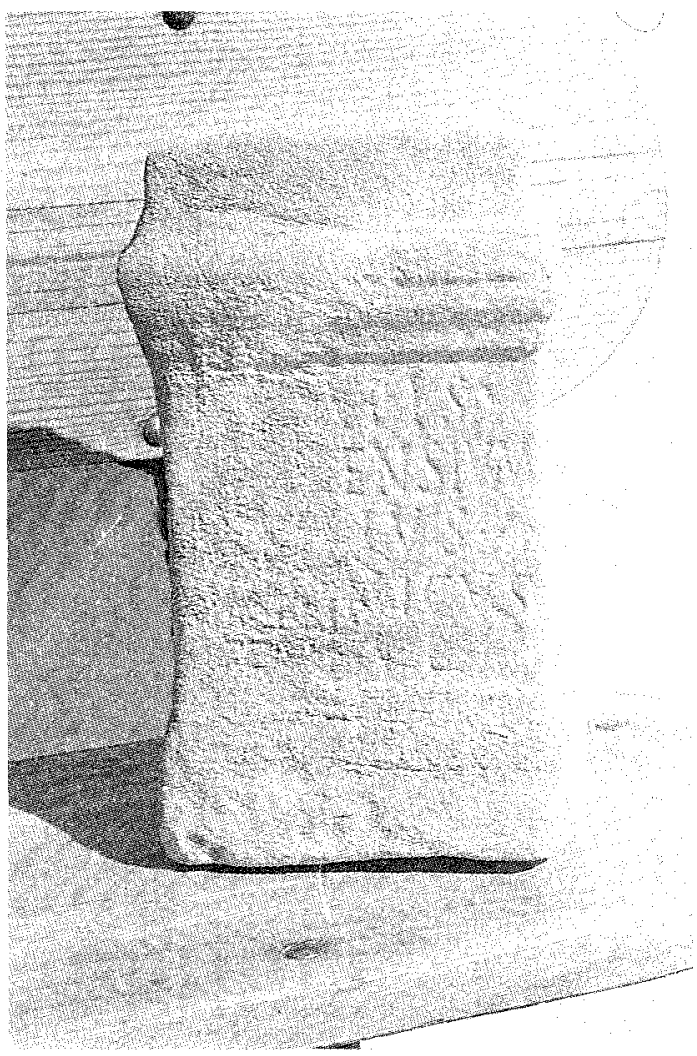

Lám. I. Inscripción votiva a las Ninfas Caparenses, que se conserva en el balneario de Baños de Montemayor.

19 Fita y Colome, F., "Excursiones epigráficas", Bolet. de la R. Acad. de la Hist., XXV, 1894, págs. 146-151. 


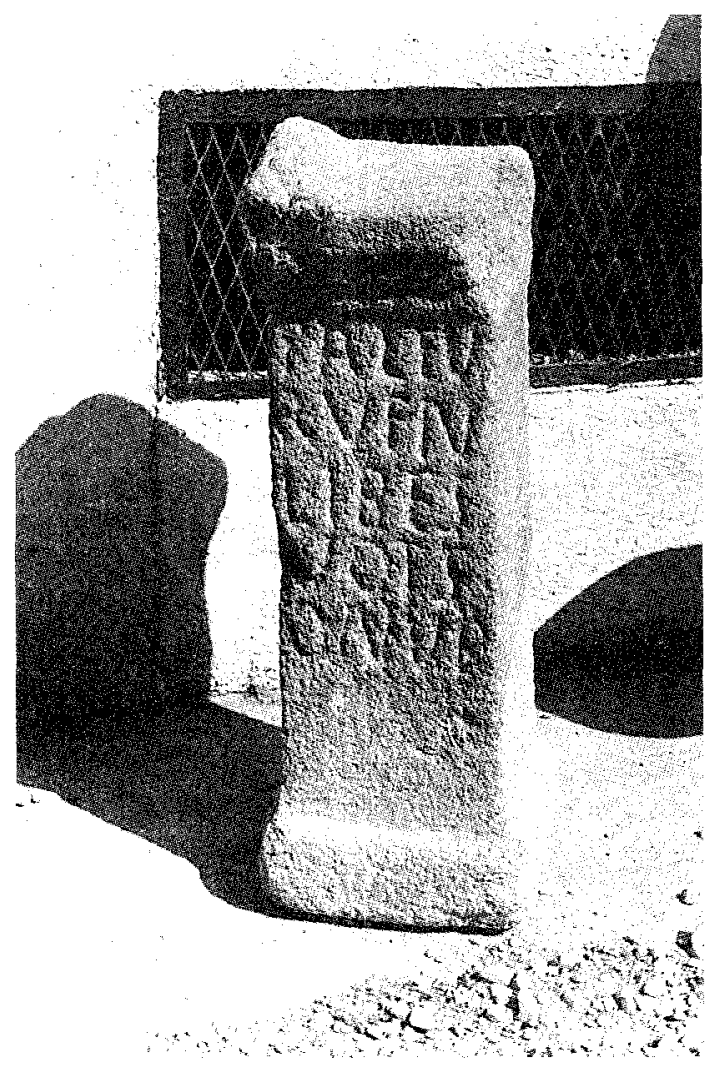

Lám. II. Inscripción votiva a Salfu (Salus ?), encontrada en Baños de Montemayor $y$ conservada en el mismo balneario.

Roldán Hervás ${ }^{20}$ sobre las 11 lápidas que pervivian, aunque en mal estado, y que se conservaban en una vitrina del edificio balneario. Éstas son las mismas que aún subsisten ${ }^{21}$.

Acerca de otros restos, sólo nos consta el testimonio detallado de Díaz y Pérez ${ }^{22}$, el cual comenta: "No lejos del sitio donde aparecieron las anteriores lápidas se encontró un verdadero filón de antigüedades, todavía

20 Roldan Hervás, J. M., art. cit, 1965, págs. 17 ss.

21 Haba Quiros, S., Catálogo epigráfico latino del partido judicial de Plasencia (Memoria de Licenciatura inédita). Cáceres, Univ. de Extremadura, 1986.

${ }_{22}$ Diaz y PÉrez, N., op. cit., pág. 170. 
intacto. En un espacio de algunos metros cuadrados y a cuatro de profundidad se recogieron cerca de 600 objetos perfectamente conservados y una multitud de fragmentos. Eran ex-votos atribuidos al templo de la Fortuna, que estuvo situado en aquel sitio». No está atestiguado epigráficamente el culto a Fortuna, que, de haber existido en aquel lugar, daria pie a hablar de una Fortuna balnearis. Más adelante el mismo autor dice: «Entre los ex-votos abundaban pies, manos, brazos, piernas y pechos de tamaño natural: también había animales domésticos, cabezas de mujer y hombre, cabezas de faunos cubiertas de pelo y estatuas representando hombres y mujeres. Estos ex-votos eran de barro cocido... En la plaza del Arenal se exhumó también un pedestal de piedra de 1,20 m de ancho por 1,40 de largo. Tenía en relieve la estatua de una mujer vestida de larga túnica y gorro frigio».

No tenemos otras fuentes para contrastar la información de Diaz y Pérez, pero, de ser cierta, supondría pensar en la existencia de uno o más santuarios de culto, no sólo a las Ninfas y divinidades acuáticas, sino también a otras divinidades orientales, quizá, aunque relacionadas con lo salutífero.

La pervivencia del culto en relación con las termas es patente, pues el mismo autor nos dice que próxima al manantial existía una antigua ermita, con la advocación de Santa María Egipciaca y a la que él data de época de los godos. En su construcción se habian reaprovechado muchisimos sillares romanos, lápidas funerarias y utres votivas dedicadas a las diosas de las aguas en recuerdo de los enfermos curados en las Thermas» ${ }^{23}$.

El Salugral, en Hervás.-Situado en un punto de fácil acceso, a unos $3,5 \mathrm{~km}$ de la localidad de Aldeanueva del Camino.

Conserva todas las dependencias propias de un Balneario del siglo pasado, aunque en la actualidad sus instalaciones se utilizan sólo como residencia juvenil de verano. Sus aguas presentan la misma composición química que las de Baños de Montemayor, aunque requieren calentamiento. El conjunto, ajardinado, está atravesado por el río Ambroz, con un puente de cierta antigüedad.

La fuente y sus propiedades se descubrieron de forma ocasional, cuando unos cerdos enfermos de dermatosis se sumergieron y curaron, según Álvarez Taladriz ${ }^{24}$. El mismo autor afirma haber hallado en docu-

${ }^{23}$ Diaz y Pérez, N., op. cit., pág. 1.172.

24 Álvarez Taladriz, L., op. cit., págs. 8-21. 
mentos muy antiguos del archivo de Béjar referencias a las propiedades de esta fuente y sus acciones sobre distintas enfermedades.

Este enclave se halla muy bien comunicado; a unos $300 \mathrm{~m}$ de la calzada de la Plata y próximo a los puentes de la Doncella y Romanillos, núcleos de paso importantes.

No conocemos restos constructivos antiguos para este centro balneario, excepto la mención de Paredes ${ }^{25}$, que habla de un arca de piedra labrada que cobija esta fuente sulfurosa y que facilita a los dolientes el disfrute de sus virtudes. El manantial primitivo, a unos $2 \mathrm{~m}$ de profundidad, es hoy visible, y en torno a él giran todas las edificaciones del recinto.

El topónimo Salugral es definitorio, pues la raíz Salu- está indicando la función primordialmente benefactora y curativa de esta fuente. El mismo caso se repite en los baños de El Salugral, en Jarilla, y creemos puede ponerse en relación con el término latino salus, en su significado de salud, pero también de vigor y energía.

El Salugral, en Jarilla. - Los baños de Jarilla se encuentran en la dehesa Cabezaolit, a orillas del arroyo de El Salugral. Aquí se ubican tres fuentes, seguramente con un mismo origen geológico. Dos de ellas están construidas con piedra de granito, adoptando la forma de una cubierta que cobija agua de olor fétido y capa de lodo, característico en este tipo de aguas. En los aledaños de una de estas fuentes y en las inmediaciones del cortijo Salugral pudimos fotografiar sillares graníticos trabajados y de grandes proporciones, un plinto, tegulas y cerámica común romana. Posiblemente pertenecian a un edificio relacionado con la fuente.

Por último, en la falda del cerro Cabeza Gorda estudiamos una tercera surgencia, de mayor monumentalidad (lám. III). Presentaba un corredor de 4,95 $\mathrm{m}$ de longitud por 1,20 $\mathrm{m}$ de anchura, con una escalera por la que se desciende a través de 20 peldaños, bien trabajados, a una cámara abovedada donde el agua se remansa.

En esta dehesa de El Salugral, Paredes ${ }^{26}$ descubrió a principios de siglo varias lápidas que supuso votos a las aguas salutíferas. De una de ellas dio el dibujo y un breve texto: IVLIV / LV, así como sus dimensiones. El resto de las aras señala el autor que eran anepigrafas. Paredes no vio restos romanos, que ahora sí se han exhumado, y, además, desconoce la tercera de las fuentes, con descenso escalonado. Atribuía a estas aguas

${ }^{25}$ Paredes Gullién, V., “Hervás», Revista de Extremadura, IX, 1907, págs. 97-106.

26 Paredes Guillén, V., op. cit., 1909, págs. 260-269. 


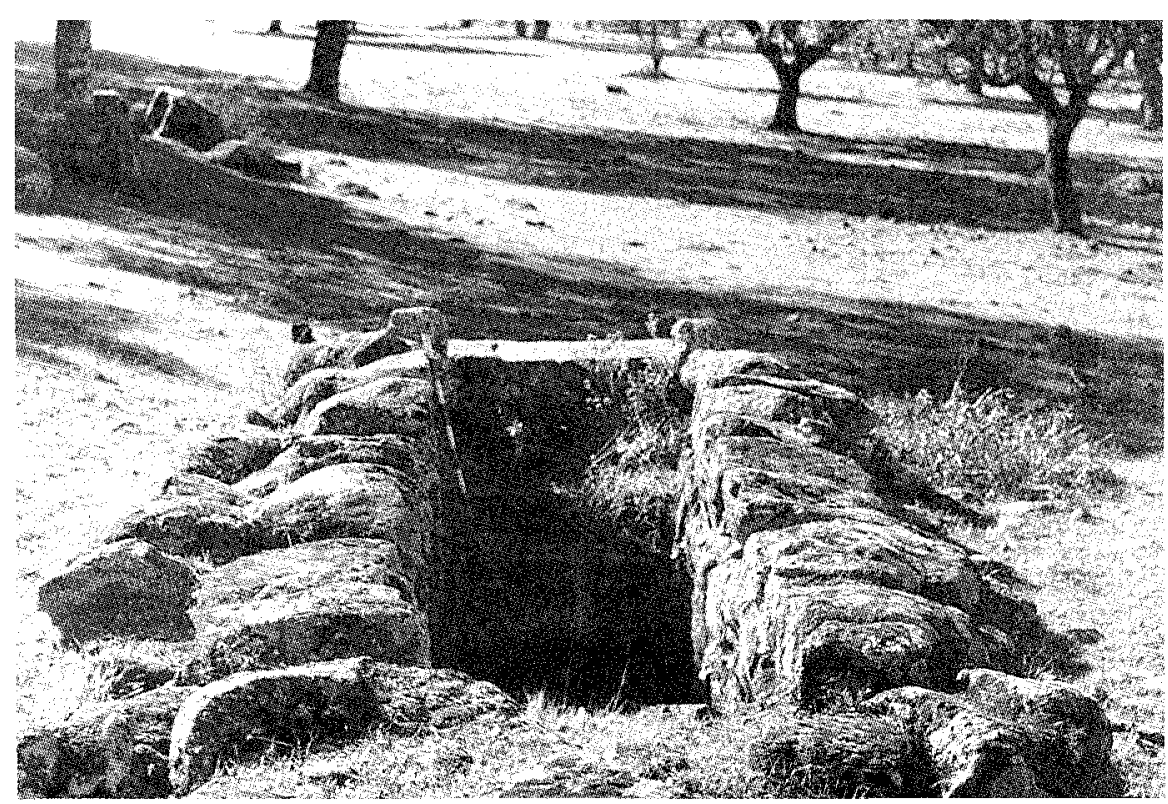

Lám. III. Escalera que desciende a un manantial subterráneo, en El Salugral, (Jarilla, Cáceres).

un acompañamiento de gases en su surgencia y los calificó como baños, aunque, en la actualidad, sólo se utiliza en bebida.

No conocemos análisis sobre sus componentes, aunque los testimonios orales recogidos les atribuyen efectos sobre las enfermedades reumáticas.

La calzada de la Plata pasa a unos $2 \mathrm{~km}$ del lugar, hacia el Este, mientras que Cáparra queda a $4 \mathrm{~km}$ al Suroeste. Recordemos cómo la mayoria de las dedicaciones votivas de Baños de Montemayor se dirigen a las Ninfas caparenses, por lo que parece ser que Baños era el centro termal y de ocio de los habitantes del enclave romano de Cáparra. Pero no podemos afirmar que fuera el único. Los datos arqueológicos y la propia existencia de ambos Salugrales, en Hervás y Jarilla, también en el territorio de Cáparra, indican que pudieron ser utilizados abundantemente en época romana, quizá por las clases más desfavorecidas. Así, la lápida dedicada a Salus, documentada en Oliva de Plasencia, pero procedente con gran probabilidad de Cáparra ( $\mathrm{ClL}$ II 806), podría referirse a cualquiera de los manantiales anteriormente citados.

En cualquier caso creemos interesante subrayar la posible existencia de otros centros salutíferos, menos estudiados y con menor vigencia en la actualidad, pero dentro de la misma área de influencia. 
Templo de Piedras Labradas, en Jarilla.-De gran interés y no exenta de polémica es esta construcción que se ubica a casi mil metros de altura, en el cerro de su mismo nombre, Piedras Labradas.

Fue Sayans Castaños ${ }^{27}$ quien publicó, por primera vez, un plano de sus cimentaciones y recogió diversas aras votivas. De ellas, tres presentaban texto epigráfico. Sayans, como en otras ocasiones, ofreció lecturas problemáticas o muy dudosas de interpretar. Con motivo de otra investigación ${ }^{28}$, intentamos reencontrar estas lápidas para releerlas, pero por circunstancias muy personales de nuestro doctor en Medicina fue imposible llegar a saber si aún existían.

De los textos en los que queda clara la fórmula votiva no puede deducirse ninguna divinidad concreta. Sin embargo, en una de las inscripciones ${ }^{29}$ se lee: CECPR.SP, que nosotros queremos ver $\mathrm{Cec}$ ? pr (o) $s$ (alute) $p$ (osuit).

El autor citado hace referencia, asimismo, a una fuente de caudal fijo cerca del templo, la cual pudimos detectar en visita realizada en 1986. Este hecho, unido a las circunstancias geográficas de su emplazamiento, la dificil accesibilidad y la panorámica del valle de las Granadillas, que desde su altura se divisa, hacen pensar en un santuario romano (y quizá anterior) dedicado al culto a las aguas no sólo como sanadora, sino intimamente relacionada con la fecundidad de la tierra y la vegetación.

Valdelazura, en Plasencia.-Balneario ubicado en la finca Alturas de Abajo, término de Plasencia y próximo, como los anteriores, a la Vía de la Plata.

Allí podemos ver una construcción de planta poligonal (lám. IV), rematada por una especie de pináculo y cuyo interior está constituido por una sencilla estancia. Ésta presenta una galería superior, con una escalera en cada lado, por las que se desciende al suelo de la cámara, embaldosado, y debajo del cual mana el agua constantemente. Para mejor aprovechamiento del agua el suelo posee aberturas de diferente tamaño y longitud, adaptadas a la forma de la roca subyacente (lám. V).

Sus aguas se usan predominantemente en bebida, con propiedades reumáticas y nefríticas. Actualmente su aprovechamiento es sólo de tipo

${ }^{27}$ Sayans Castaños, M., op. cit., 1957, págs. 210 ss.

${ }^{28}$ Haba Quirós, S., op. cit., 1986.

${ }^{29}$ Sayans Castaños, M., op. cit., pág. 214. 


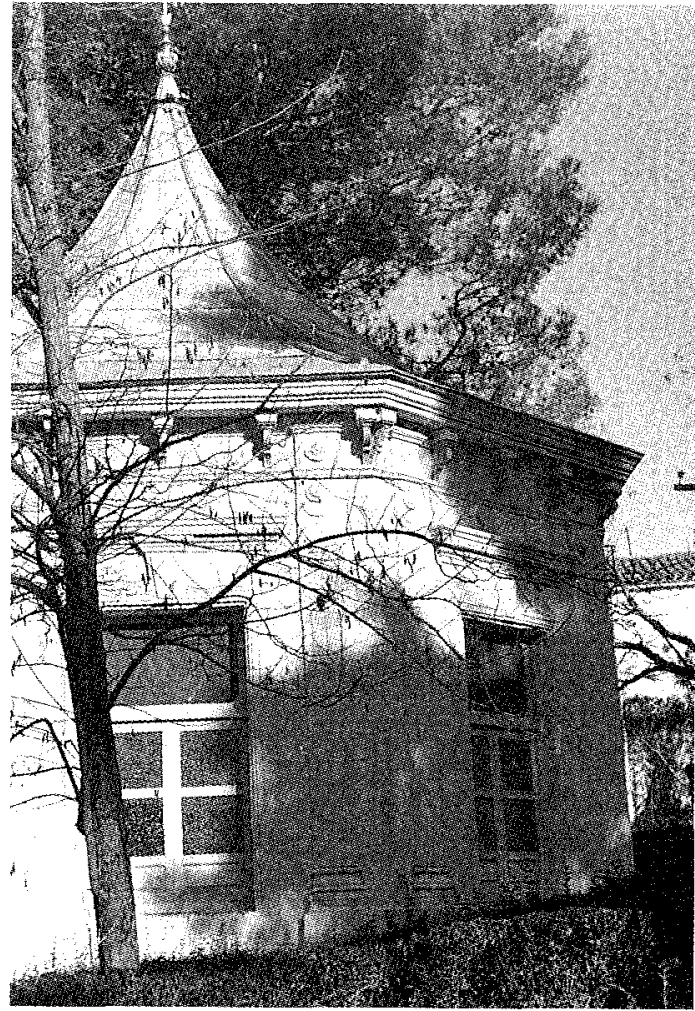

Lám. IV. Edificación que cobija el manantial del balneario de Valdelazura (Plasencia, Cáceres).

familiar. Conocemos dos Memorias médicas realizadas a principios de siglo, donde se ponderan sus cualidades ${ }^{30}$. Además, sabemos que el antiguo dueño, don Ángel Delgado, las dio a conocer y promovió su comercialización embotellada, ya en el siglo $x \mathrm{xx}^{31}$.

Por todo el recinto de la finca se hallan esparcidos diversos restos arqueológicos: basas de columnas, sillares labrados, piedras de molinos, etcétera. El Doctor Rodríguez Pinilla, en 1910, ya se dio cuenta de este hecho cuando afirma: «En la dehesa Alturas de Palacios y en las cerca-

${ }^{30}$ Rodriguez Pinilla, H., op. cit., 1910; doctores Giral y Angoso, Memoria de las aguas mineromedicinales de Valdelazura (Plasencia). Salamanca 1909.

31 Jaraquemada, M. ${ }^{\text {a }}$., "Balnearios extremeños. Las hermosas fuentes de la salud", $P S N$, 12. Madrid 1985, págs. 20-23. 


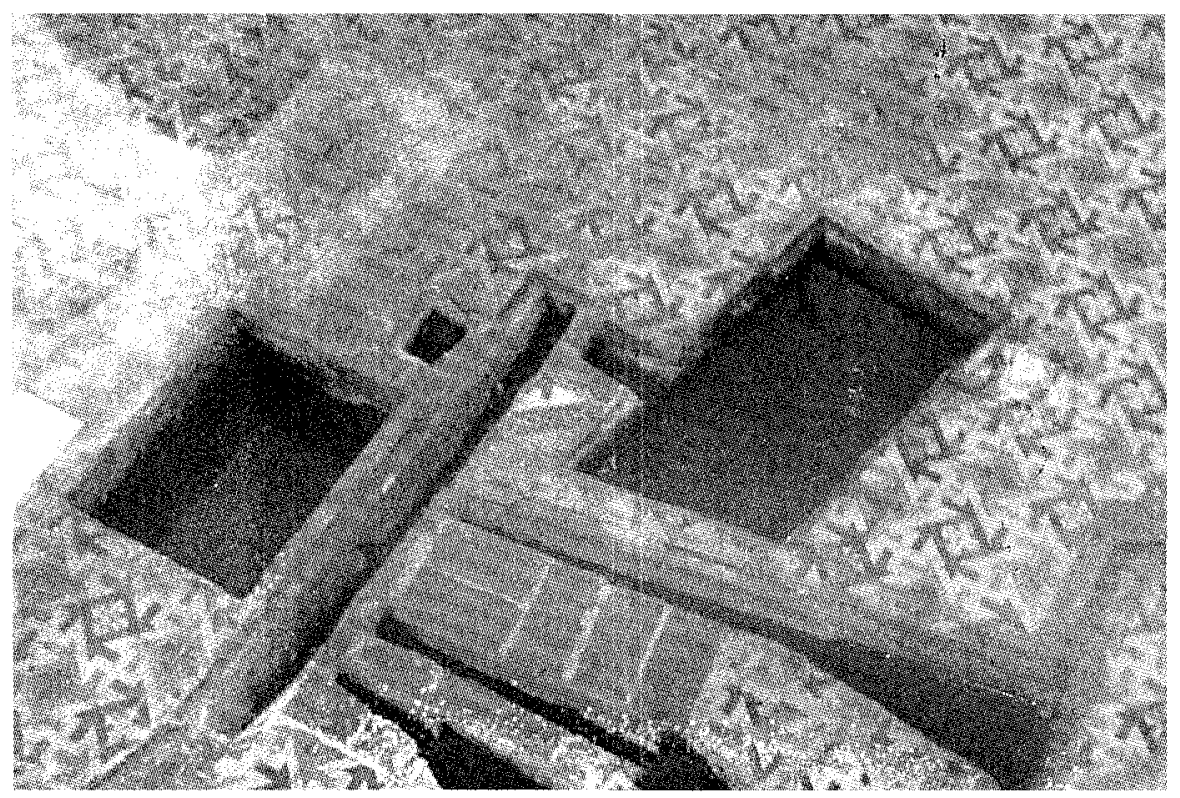

Lám. V. Arquetas acondicionadas para servirse del manantial en el balneario de Valdelazura (Plasencia).

nías de la fuente de Valdelazura se han encontrado en las excavaciones hechas monedas de Trajano, aras, columnas y otras pruebas que hacen pensar en que era conocida ya por sus virtudes». Por su parte, RíoMiranda ${ }^{32}$, historiador de la zona, ha encontrado restos que permiten hablar de un asentamiento rural romano de considerables dimensiones, así como una necrópolis, de la que se han exhumado varias tumbas. Nosotras mismas, con motivo de trabajos anteriores ${ }^{33}$, fotografiamos, además de los vestigios constructivos, dos lápidas funerarias en el jardín de la finca. Ambas presentaban onomástica totalmente indigena y con dedicantes de clase servil.

Creemos, por otro lado, poder aducir elementos de culto al agua en relación a este balneario, hoy inactivo. Nos basamos para ello en dos pequeñas lápidas (láms. VI y VII), en deficiente estado, encontradas en el mismo. Una de ellas se halla fragmentada, por lo que nada seguro se puede afirmar. La segunda está constituida por el fragmento superior de

\footnotetext{
32 Rí-Miranda, J., art. cit., 1981.
}

33 Haba Quirós, S., op. cit., 1986. 


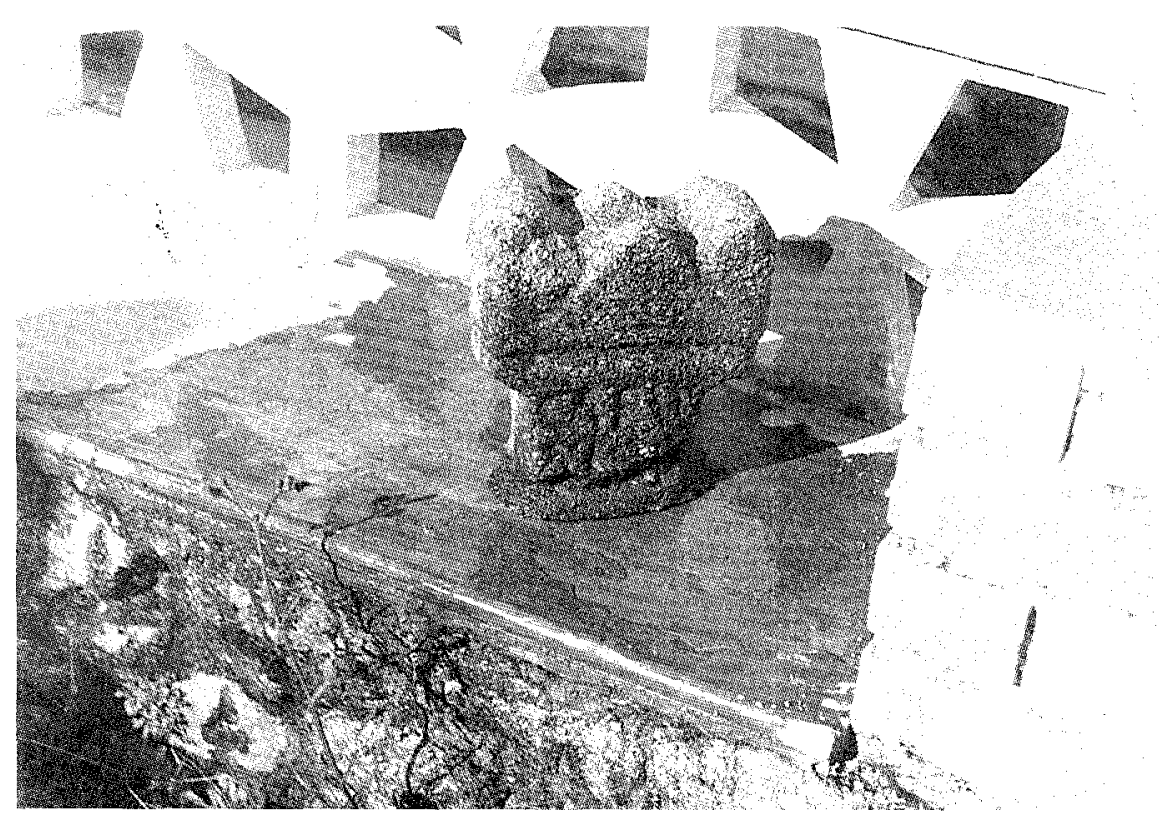

Lám VI. Ara votiva encontrada en el balneario de Valdelazura y dedicada a Safy o Saly (Salus?).

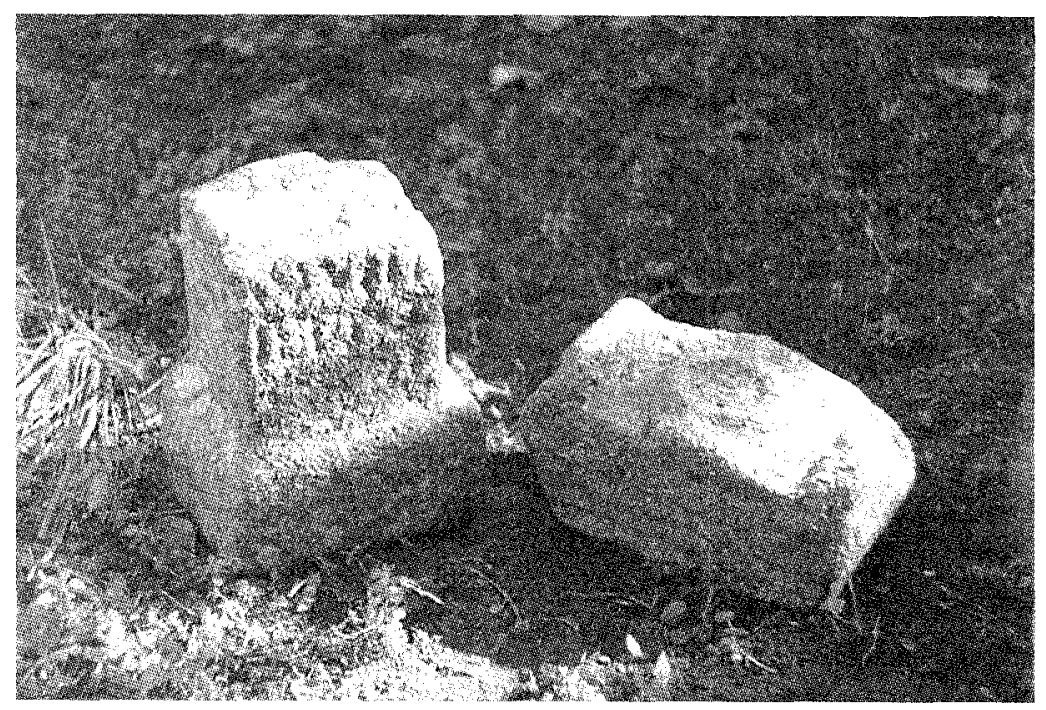

Lám. VII. Lápida votiva fragmentada procedente del balneario de Valdelazura. 
un ara, en el que se lee como encabezamiento y con gran dificultad: SAFV / S T. Nosotros hemos interpretado esta inscripción como: Safv / s (acrum) T..., siendo Safu alguna variante indígena de Salus. Para ello nos basamos en la lápida de Baños de Montemayor, donde no se escribe Salus tampoco, sino SALFV. Esta misma lápida de Baños presenta otras irregularidades como libes por libens, además de varios defectos de grafía.

Santa Marina, en Ahigal.-Con el nombre de Santa Marina la Vieja se conoce un lugar sito en el paraje denominado Las Canchorras, del término de Ahigal, cerca del arroyo Palomero. Se encontraba allí una ermita con aquel nombre y desaparecida a principios del siglo XVII, y una fuente que aún persiste.

Restos arqueológicos nos hablan de una continuidad del poblamiento desde, al menos, la Edad del Bronce. Entre los hallazgos cabe destacar un verraco de granito y varios petroglifos y grabados rupestres ${ }^{34}$.

En 1981, al hacer una charca, con destino al ganado, fue exhumada un ara votiva, hoy conservada en el Ayuntamiento de Ahigal (Iám. VIII). Su texto es el siguiente: REINVS / [C] ILI. MAR / V.S.L.A. El antropónimo Reinus no está documentado, pero sí Arreinus y Arrenus, frecuente dentro y fuera de Lusitania. Beltrán ${ }^{35}$ interpretó el epígrafe con la lectura: (Ar) reinus / (f) ili (us) Mar (ci) / v (otum) s (olvit) I (ibens) a (nimo). Para Beltrán se trataba de una dedicatoria a una divinidad indeterminada y que estaba ya implícita en el carácter del monumento. En este caso podría ser una divinidad relacionada con el agua.

No nos parece probable una dedicatoria a Marte, desarrollando Mar (ti), como sugiere Salas Martín, en noticia oral.

En todo caso, la divinidad Mar..., en cualquiera de sus interpretaciones, se conservó después en el topónimo cristianizado, Santa Marina ${ }^{35}$.

Santa Marina, en Casas de Millán.-Volvemos a encontrar aquí la conexión entre una fuente mineromedicinal y un fenómeno de cristianización con el nombre Marina.

La fuente o pozo de Santa Marina se emplaza a $2 \mathrm{~km}$ al Noroeste de Casas de Millán y a $1,5 \mathrm{~km}$ de la Vía de la Plata. En sus inmediaciones se halla el cerro de Cáceres el Viejo $(768 \mathrm{~m})$, importantísimo yacimiento,

\footnotetext{
${ }^{34}$ Domínguez, J. M., «Los grabados rupestres de El Torero, en Las Canchorras", Boletín Amigos de Ahigal, núms. 30 a 34. Ahigal, diciembre 1982-enero 1983.

${ }^{35}$ Beltrán Lloris, M., "Aportaciones a la epigrafía y arqueología romanas en Cáceres», Caesaragusta, 39-40. Zaragoza 1975, pág. 79

36 Dominguez Moreno, J. M., y Paniagua, M., art. cit., 1881.
} 


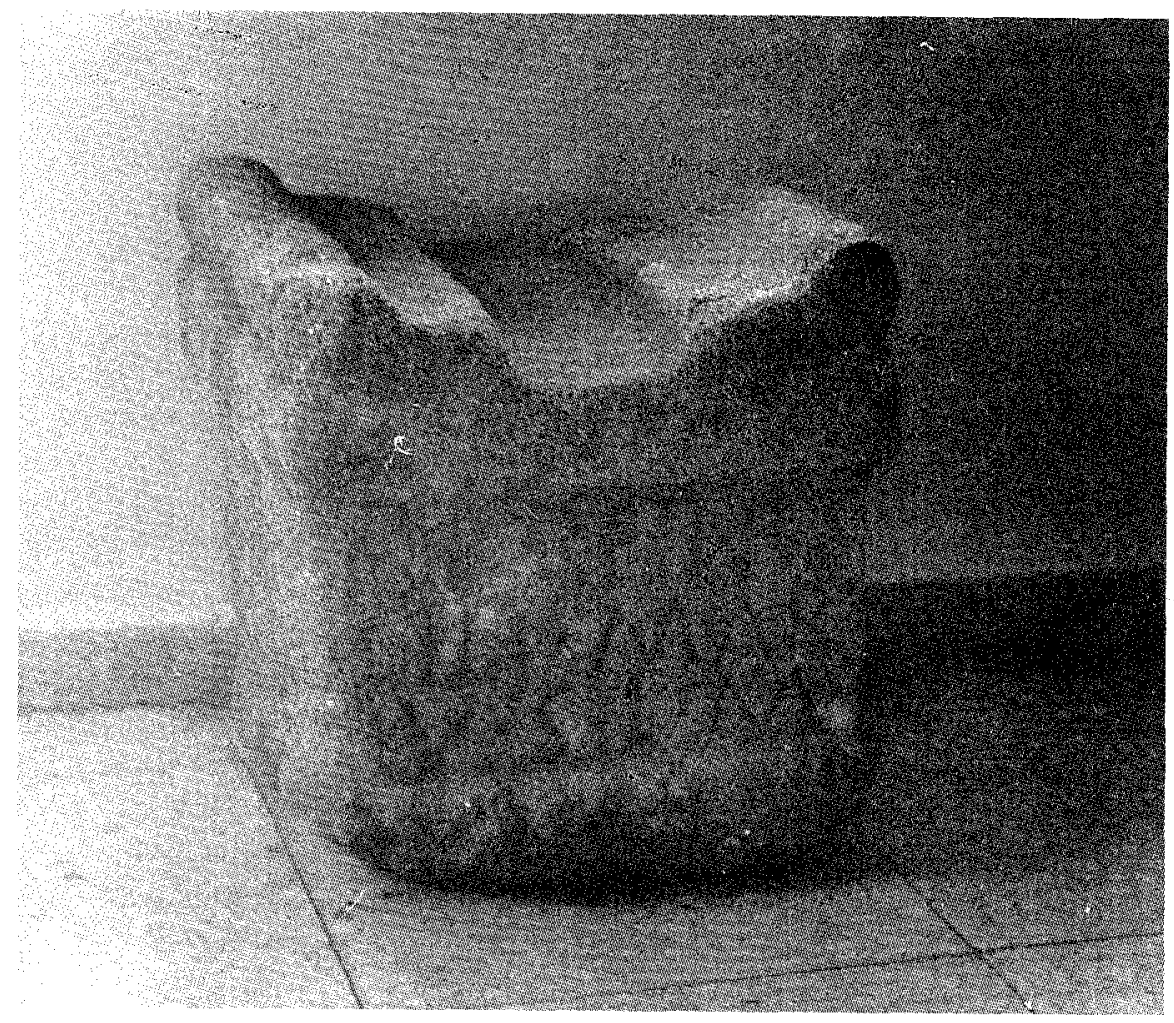

Lám. VIII. Ara votiva consagrada a Mar (ti ?), procedente de la zona «Las Canchorras», en Ahigal (Cáceres).

probable campamento romano que debió jalonar la ruta de Metelo hacia el Norte.

Las propiedades benefactoras de la fuente son bien conocidas por tradición entre los vecinos de la comarca, que la ingieren en bebida. Incluso existió un rústico comercio de este agua en pueblos de la zona.

Como elementos de culto, hasta la fecha, sólo hemos encontrado las ruinas o cimentaciones de la antigua ermita a Santa Marina, seguramente medieval, pero que pudo ser heredera de otra edificación anterior. No se han hallado, por el momento, epigrafes votivos susceptibles de relacionarse con esta fuente salutífera. Sin embargo, hay que resaltar el topónimo como uno de los más frecuentes vinculados a las aguas medicinales. A este respecto, y como dato a añadir, C. Matas nos aporta por comunicación escrita que en algunos santuarios de Galicia existe un ritual 
en el que se dan tres golpes con la cabeza de Santa Marina, contra una roca, para que brote agua.

Otros ejemplos muy interesantes se pueden rastrear en la región extremeña. Así, en Zarza Capilla (Badajoz) se documenta una ermita arruinada dedicada a Santa Marina ${ }^{37}$. Esta santa era bajada desde su parroquia, en la tarde de Pentecostés, y era recibida por los romeros de otros pueblos aledaños, Peñalsordo y Capilla. Era conocida, popularmente, como la "Virgen de la Culebra», por la serpiente que iba enroscada a sus pies. A la puesta del sol los devotos regresaban, acompañados de oraciones, con otra santa, Santa Catalina. Llama la atención el que se relacione a Santa Marina con la culebra, teniendo en cuenta que a la Salus romana se la representaba con una serpiente. Por otro lado, la asociación de Santa Marina y Santa Catalina a las aguas medicinales la veremos más adelante en el caso de Brozas (Cáceres).

Fuentidueñas, en Plasencia.-A $5 \mathrm{~km}$ al Sur de dicha ciudad, en el km 135 de la carretera $\mathrm{N}-630$, se alza una ermita medieval dedicada a Nuestra Señora de Fuentidueñas. Hoy ha quedado convertida en establo de ganado.

En su construcción se han reaprovechado elementos romanos, bien visibles, por ejemplo, en los sillares almohadillados del basamento. Mélida ${ }^{38}$ cree que debió tratarse de un templo, aunque llama la atención sobre el hecho de que se encuentre aislado. Desconocemos los motivos por los que se erigió, pero a nuestro juicio estaría ligado a la fuente que, hoy cegada, existía al Noroeste de la ermita y que bien pudo tener un carácter sagrado, unido a posibles cualidades medicinales. El testimonio de Mélida habla de una construcción de sillería granítica, cuadrada, de $2,11 \times 0,45 \mathrm{~m}$, la cual cobijaba la fuente. Su morfología la hace similar a otras que hemos estudiado para la zona, lo que, unido a su topónimo, hacen pensar en una relación del santuario con el manantial, desde época medieval. Para el período romano la documentación se centra, en principio, en la cimentación. Pero poseemos, además, dos epígrafes. Uno de ellos es muy probablemente funerario, aunque se conservaba sólo un fragmento que fue hallado en las gradas de la ermita. Más interés tiene para nosotros otro fragmento muy deteriorado que se encontró en unas viviendas de campo próximas a la misma ermita. (...) Sólo son apreciables dos líneas inscritas: ... / ...ANF ... / ...V L ... En nuestra opinión, podría tratarse de la parte inferior de un ara votiva, con parte de la fórmula ...v

${ }^{37}$ Muñoz Rubio, J., El Estado de Capilla, 1985, pág. 304.

38 MÉlidA, J. R., op. cit., 1914-16, págs. 163-64. 
(otum) I (ibens), dedicatoria a alguna divinidad o fuerza salutifera, vinculada al agua de la fuente inmediata.

Fuente Santa, en Galisteo.- - La información oral aportada por don Antonio Sánchez Paredes, eminente investigador placentino, nos condujo al lugar Ilamado Fuente Santa, en Galisteo. Emplazado en una elevación del terreno, en las inmediaciones del cementerio municipal y distante del río Jerte un kilómetro. Próximo al lugar se halla el arroyo denominado Fuente Vieja.

En la prospección realizada no se encontró ninguna fuente visible, aunque si el sitio donde había sido cegado un manantial natural, lo que fue confirmado por el dueño de la finca. En los aledaños se hallaban diseminados abundantes restos de tegulas, ladrillos y algunos sillares labrados que fotografiamos.

Buceando en las noticias bibliográficas, observamos que Escobar Prieto ${ }^{39}$, a comienzos de siglo, nos confirma la ubicación allí de un convento de dominicos, destruido totalmente tras la desamortización, pero que Ponz aún pudo ver ${ }^{40}$. Escobar también hace referencia a una ermita dedicada a Nuestra Señora de Fuente Santa que formaba parte del convento.

Por último, en una casa particular de la villa de Galisteo se conserva hoy una lápida de mármol que estuvo empotrada en el muro exterior de la ermita y recuerda los nombres de los fundadores (García Fernández, Conde de Osorno y su esposa, Maria de Luna). La inscripción comienza así: Hoc fo (n) tis loco prius corusco miraclis / D. Garcia Fernandes Marrique Comes... de forma que se establece una estrecha relación entre la ermita y su advocación con la existencia de una fuente de tradición "milagrosa", cuyo culto se remonta a épocas muy antiguas. Sin duda, poseyó propiedades benéficas, pues las noticias orales recogidas en la localidad nos hablan de una utilización destinada a la curación de enfermedades oculares.

Ningún elemento de culto de época romana se puede aducir, hasta la fecha, referente a esta fuente.

Baños de Cabezón, en Cañaveral.-A unos $500 \mathrm{~m}$ de la calzada de la Plata y en paraje retirado y frondoso. Presenta agua manante, de color azulado, indicada en afecciones reumáticas. Atravesada por el arroyo Rivera de Cabezón, la fuente propiamente dicha se cobija con una cubierta

39 Escobar Prieto, E., art. cit., 1906, págs. 74 ss.

40 Ponz, A., op. cit., lib. VIl, pág. 43. 
construida por lajas de pizarra, de aspecto enormemente rústico. Existen instalaciones de baños con piletas muy primitivas para calentamiento del agua. En sus proximidades se encuentra la mina de «La Nava», con explotación de casiterita, hecho que origina la aparición de filones hidrotermales.

Cuenta con una ermita dedicada a Nuestra Señora de Cabezón, el mismo nombre del arroyo, imagen en honor de la cual se celebra romería en el mes de mayo. Volvemos aquí a encontrar la asociación de un centro de culto cristiano y una fuente salutífera. No se poseen otras noticias de culto o veneración de este agua, aunque es posible intuir, como en el ejemplo anterior de Galisteo, una continuidad desde épocas más antiguas. Baste recordar el ya muy citado testimonio de Plinio ${ }^{41}$ acerca de las fuentes de Tamarico en Cantabria, que ha conservado su carácter hoy con el nombre de San Juan de las Aguas Divinas.

\section{AGUAS MINEROMEDICINALES, SACRALIZACIÓN Y PERVIVENCIAS EN EL CULTO}

Este mismo fenómeno de pervivencia, basado en la toponimia, cabria ser investigado profundamente para otros múltiples puntos de la región extremeña. Jerez de los Caballeros (Badajoz) cuenta con una fuente curativa, de la que nos hablan las Crónicas franciscanas, próxima al Convento de Aguas Santas y con la advocación de Nuestra Señora de Aguas Santas; también en Higuera la Real (Badajoz) se documenta la existencia de una Fuente de Aguas Santas y una ermita arruinada dedicada a la misma Virgen. Otro testimonio interesante lo constituye la ermita y fuente de Fuente Santa en Zorita (Cáceres). El manantial se halla cobijado por un templete de cierto gusto artístico. El culto se remonta al siglo $\mathrm{XI}^{42}$. En un desván de la ermita pudimos ver unas curiosas pinturas, de aire ingenuo y colores vivos, firmadas por un autor del siglo xVIII, que represen-

41 Blázquez Martinez, J. M., Imagen y Mito. Madrid 1977, pág. 323. 1962.

42 Fernández SÁnchez, T., Historia de la imagen de Ntra. Sra. de Fuente Santa (Zorita), 
tan a peregrinos en procesión en acción de gracias y a la Virgen acompañada de la fuente.

Otros muchos casos nos mostrarían cómo, en efecto, existe una asociación generalizada en el ámbito cristiano entre las surgencias de agua con poderes bienhechores y las figuras de la Virgen y Santos. No contamos para ellos testimonios más antiguos que puedan verificar su utilización y relación cultual en época romana.

Estos mismos fenómenos de continuidad están siendo estudiados en la vecina Portugal, por parte de Cardim Ribeiro. En su obra sobre cultos acuáticos del territorio de Olisipo ${ }^{43}$, documenta un ara votiva a Fons, por Atilia Amoena y que fue hallada en Ericeira. En la misma localidad existen hoy unas aguas con ricas propiedades terapéuticas, denominadas Aguas de Santa Marta, con ermita de la misma advocación. Este mismo autor clasifica los testimonios en directos e indirectos potenciales. Estos últimos se refieren a fuentes o manantiales cuyo uso medicinal es conocido, pero aún no se puede confirmar la eventual sacralización de sus aguas.

No obstante, por toda la geografía extremeña encontramos multitud de aguas con características "especiales» que sí fueron sacralizadas, al menos desde el periodo romano. Ya vimos anteriormente un grupo de ellas que presentaban una alineación inequívoca con una vía importante de comunicación y con un accidente geológico.

Otros lugares que podrían aducirse son:

Alange (Alange, Badajoz).-Conocidísimo balneario, con categoría de Monumento Nacional, a $18 \mathrm{~km}$ de Mérida. La zona, por su tectónica, es propicia para la surgencia de fuentes a altas temperaturas.

El actual balneario aprovecha parte de las antiguas termas romanas, a las que se han añadido nuevas instalaciones. De aquéllas merecen destacarse las dos piscinas circulares o rotondas, con bóveda de media naranja y oculus de cierre en la parte superior. Poseian pinturas de tema oceánico ${ }^{44}$, hoy perdidas. En ellas se ubican dos piscinas circulares, posiblemente para baños masculinos y femeninos por separado. Se des-

${ }^{43}$ Cardim Ribeiro, J., "Contributos para o conhecimiento de cultos e devoçoes de cariz aquático relativos ao territorio do Municipio Olisiponense", Boletim Cultural da Assembleia Distrital de Lisboa, IIl Serie, núm. 89, 1. ${ }^{\text {er }}$ tomo. Lisboa 1983, págs. 3-41.

${ }^{44}$ Álvarez Martinez, J. M., art. cit., 1980, pág. 17. 
ciende a ellas por escalinatas y constituyen, para G. Mora ${ }^{45}$, un ejemplo perfecto de laconicum, tal como lo describe Vitruvio. Otros elementos que se conservan son la escalera de bajada a las salas de baños (lám. IX) lienzos de muros visibles en un jardin trasero, además de otros aislados: columnas, basas, etc.

Nos interesa, sobre todo, el ara votiva que hoy podemos contemplar en uno de los patios interiores del centro termal. Está consagrada a Juno

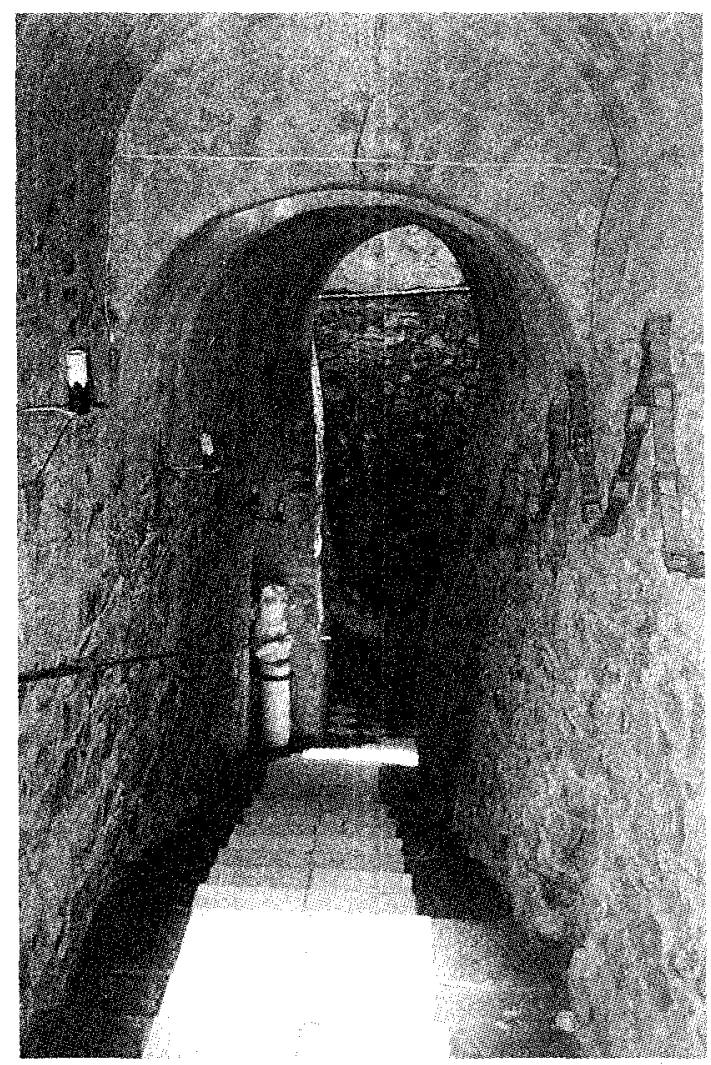

Lám. IX. Escalera de bajada a las piscinas circulares romanas, en el balneario de Alange (Badajoz). drid.

${ }^{45}$ Mora, G., Termas romanas en España (Tesina inédita), Universidad Autónoma de Ma- 
por Licinio Sereniano (que fue gobernador en Capadocia) ${ }^{46}$ y su esposa, por la curación de su hija Varinia Serena. En este caso Juno, diosa romana protectora de la mujer, actúa a través del agua para resolver un problema, posiblemente de orden ginecológico.

Álvarez Martínez, ya citado, habla de una posible zona sagrada, constituida por un templo romano, quizá un ninfeo, y lo imagina como un edificio sobre un criptopórtico, al modo arquitectónico de la Lusitania romana. Posteriormente dicho templo arruinado habría sido sustituido por una basílica visigoda. Debido a este mismo fenómeno de continuidad, hoy podemos ver allí una ermita con pórtico lateral de arcadas, dedicada al Cristo de los Baños.

Baños de San Gregorio, en Brozas (Cáceres).- Ubicado al Este de la población y en paraje de dehesa, abrigado de los vientos y con amena vegetación. Las instalaciones para baños, de enorme simplicidad, forman cuerpo con el edificio de la pequeña ermita que contiene la imagen del santo. El manantial primario se halla en el exterior, protegido por arqueta. Sus aguas, de composición sulfurosa, presenta el típico olor y sabor a huevos podridos.

Ya a mediados del siglo pasado los describía Madoz ${ }^{47}$ como de maravillosos efectos, curativos y dignos. En verdad, aun contando con infimas instalaciones, un gran número de gente lo ha seguido usando a lo largo del tiempo. Hace dos años ha sido objeto de un acondicionamiento por parte de la Junta de Extremadura, que le ha dotado de varias habitaciones y servicios para mejor acomodo de los usuarios. Figura en estos momentos en la Guía regional de Balnearios oficiales.

Casi sin duda, estas aguas fueron conocidas y utilizadas en época romana. La zona, bastante próxima al puente de Alcántara, nudo importante de paso, presenta una gran intensidad de asentamiento, con abundancia de villas y poblados bajoimperiales y abundantisimos restos arqueológicos procedentes de los mismos.

Sin embargo, no poseiamos ningún testimonio que certificara una posible sacralización o relación de culto hacia estas aguas. Por ello concedemos gran relevancia al documento epigráfico aportado por Herrera y Gil ${ }^{48}$. Se trata de una lápida aparecida en la dehesa de San Juan de Brozas, pero que posiblemente fue trasladada de su emplazamiento original. Su lado izquierdo ha sido rebajado, con pérdidas de letras, por lo que

\footnotetext{
46 Álvarez Martínez, J. M., art. cit,, 1980, pág. 17.

${ }^{47}$ Madoz, P., op. cit., 1845, pág. 670.

49 Herrera, G., y Gil. Montes, J., art. cit., 1984.
} 
resulta algo arriesgada su interpretación. La lectura del texto, por parte de dichos autores, es la siguiente: (M)AXVM / (V) S. VLAT / (I) Cl. F. TA / (P) (O) RVS / (N) A (B) IAE / (SA) CRVM.

Según esto, la dedicatoria está dirigida a Nabia, diosa indígena relacionada con el mundo acuático. Su culto, como sabemos, se concentra predominantemente en el Norte y Noroeste de la Península. Sin embargo, progresivamente se van acrecentando otros hallazgos procedentes de la provincia de Cáceres. Para el caso de Brozas, en concreto, además del epigrafe publicado por Herrera y Gil (interesante por otros motivos), contábamos ya con otra inscripción dedicada a D (eo) Navi (e), recogida en CIL II 756. También en ésta, como en la anterior, el dedicante presenta onomástica puramente indígena.

A la vista de estos dos testimonios, es verosimil pensar en una vinculación directa de los mismos con las surgencias de aguas mineromedicinales de la zona. Sin ir más lejos, en las proximidades de estos mismos Baños de San Gregorio, se halla otra fuente sacralizada, sita en la dehesa de Fuentemadero, y con la advocación de Santa Catalina. Pero, además, en trabajos realizados por nosotras ${ }^{49}$ han sido documentados otros puntos con aguas medicinales, en esta misma área. Entre ellos están el balneario de Las Cañas, en Ceclavín, intermitentemente cubierto por la presa de Alcántara, y los baños de Los Cañitos, en Zarza la Mayor, ambos con agua termal. Todos ellos participan, por otra parte, de un mismo accidente geológico constituido por una línea de fractura tectónica ${ }^{50}$, similar a la de Ávila-San Vicente. Recordemos que el manantial de Los Cañitos se nutre, muy probablemente, del mismo manantial que las reconocidas termas de Monfortinho (Portugal), muy próximas al lugar.

Otra zona importante por la densidad de manantiales mineromedicinales y los elementos de culto antiguo que ofrece es, en nuestra opinión, la que se extiende por el ámbito de las sierras de Montánchez y San Pedro, en la provincia de Cáceres (fig. 3). Se trata, como sabemos, de sierras cuarcíticas alineadas desde la frontera portuguesa hasta Aljucén. Dentro de sus materiales litológicos, los más permeables y propicios para dar caudales de aguas subterráneas son, obviamente, los más antiguos y de tipo calcáreo. Por otra parte, existe en esta comarca una notable riqueza minera, aunque no posea hoy ninguna explotación en activo. Hay bastantes puntos de composición ferruginosa, de ahi las numerosas Fuentes "herrumbrosas" que se halian; otros están compuestos por plomo,

\footnotetext{
${ }^{49}$ Haba Quirós, S., y Rodrigo LóPEZ, V., «Aguas medicinales y tradición popular en Extremadura", Cuadernos Populares, núms. 37 y 39 . Mérida, Ed. Regional, 1991.

${ }^{50}$ Los datos geológicos proceden de Juan Gil Montes, profesor de Geología (Cáceres).
} 


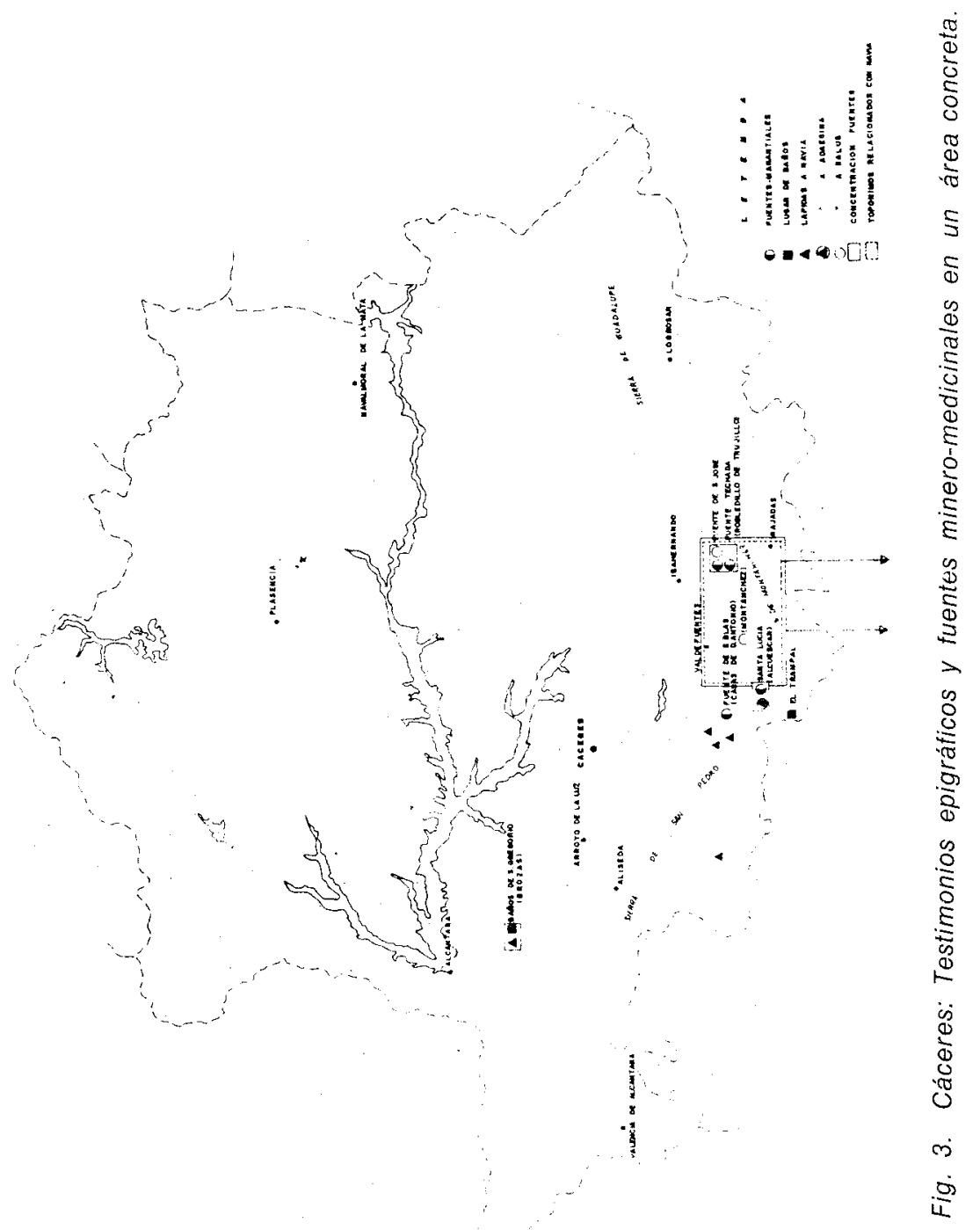


fosforita, antimonio y también hay indicios en la antigüedad de explotación de plata y oro ${ }^{51}$.

Uno de los ejemplos más sobresalientes lo constituye la ermita de Santa Lucía, en el término de Alcuéscar, dada a conocer a los investigadores por el geólogo cacereño J. Gil Montes. En el momento de su descubrimiento se encontraba cumpliendo funciones de establo y vivienda rústica.

Se halla ubicada en el paraje denominado El Trampal (trampal = sitio pantanoso, atolladero), que reúne unas condiciones de aislamiento, amenidad y frescura dignas de tenerse en cuenta, adquiriendo caracteres casi de microclima. Éste permite, por ejemplo, el crecimiento de naranjos y una determinada vegetación en ese entorno concreto.

La ermita, cuya primera publicación debemos a Rosco, Téllez y RíoMiranda ${ }^{52}$, ha sido excavada en sucesivas campañas por Caballero Zoreda y también recientemente ha sido objeto de restauración.

Desde que se dio a conocer el monumento quedó claro que nos hallábamos ante una iglesia visigoda, muy bien conservada, y que aportaba relevantes datos referidos a su estructura constructiva y a su decoración. Cabe destacar, a este respecto, cabecera, de triple ábside independiente que la hace única en su género, junto a los desaparecidos de San Juan de Baños (Palencia).

En el mismo lugar, y en un área de unos $400 \mathrm{~m}$, se encontraba otra ermita, destruida no hace mucho tiempo, con la advocación de Santiago y una tercera que no ha subsistido, a no ser en su topónimo, Cerro de la Ermita, y algunas huellas de muros. Por todo ello, Rosco, Téllez y RíoMiranda ${ }^{53}$ hicieron notar la probable existencia alli de un complejo monástico que arrancaba de tiempos hispanovisigodos. El motivo por el que pudo asentarse en este paraje tal conjunto de ermitas tiene indudables puntos de contacto con nuestro tema de estudio.

Por las inmediaciones de dicho entorno corre el manantial de El Trampal, de aguas ferruginosas, con propiedades curativas, previo calentamiento. Existia un establecimiento para tal fin, pero fue destruido por las obras de canalización del venero. Actualmente sólo sirve para el consumo de la población y son muchas las personas que acuden de la comarca para llevarla, por sus cualidades. La fuente es de caudal permanente, con

\footnotetext{
${ }^{51}$ Datos geológicos debidos a Juan Gil Montes.

52 Rosco, J.; Tellez, M. L., y Rio-Miranda, J., "Santa Lucia de Alcuéscar», Historia 16, núm. 77, sept. 1982, págs. 123-128.

53 Rosco, J.; Téllez, M. L., y Río-Miranda, J., art. cit., 1982, pág. 123.
} 
unos cinco litros por segundo, de forma que incluso movía la piedra de un antiguo molino. Por tanto, se puede afirmar que hubo conexión entre las fuentes minerales de la zona y el santuario visigodo.

Pero aún debemos reseñar otro importante dato. En la edificación de la iglesia de Santa Lucía se han reaprovechado distintos materiales que, de forma evidente, nos remiten al período romano. Esto, que ya era claramente visible, se ha confirmado con las excavaciones arqueológicas realizadas y han llevado a pensar a Caballero Zoreda en la existencia de un templo pagano anterior.

Entre los elementos reutilizados sobresalen las lápidas funerarias y votivas, dedicadas éstas a Adaegina y en número de cinco. Por lo que sabemos, Adaegina o Ataecina es una de las deidades indígenas que, junto con Endovellicus, cuenta con un número elevado de dedicaciones en la Península, con un culto muy extendido entre el Tajo y el Guadalquivir. Su función o atribuciones son conocidas a través de la asociación con una divinidad romana. Proserpina, que aparece en un epigrafe de Mérida (CIL \| 461). Además, el área de su culto se corresponde con el de Proserpina. Por estas razones se atribuye a Ataecina un carácter infernal en relación con el mundo de ultratumba y el reino de lo oculto; la etimología parece confirmarlo, aunque más débilmente, a partir de *at,oscuro, noche ${ }^{54}$.

Sin embargo, dada la concentración de testimonios en Santa Lucía de Alcuéscar y teniendo en cuenta las características ya señaladas para este área, podemos apuntar aqui no sólo la probable existencia de un templo romano de culto a las aguas anterior al visigodo, sino la posibilidad de que entre las atribuciones de Adaegina se halle la de ser protectora de las aguas, divinidad salutífera e incluso de la fertilidad y la vegetación.

Tenemos, además, localizadas en esta misma área de Montánchez un grupo numeroso de fuentes o manantiales, con previsible composición mineromedicinal y emplazadas en lugares agrestes: Fuente de San José, Fuente Techada, Fuente Matasanos, Fuente de La Nava, varias fuentes «herrumbrosas" y los Baños de El Trampal en el término de Carmonita, de propiedad privada pero dotados de instalaciones para explotación al público. Si las analizamos aisladamente, quizá carezcan de significación a efectos del presente trabajo. Pero adquieren una nueva luz, si se ponen en relación con varias inscripciones que han ido apareciendo en diversas épocas y dedicadas a divinidades de carácter salutífero.

\footnotetext{
${ }^{54}$ López Melero, R., «Nueva evidencia sobre el culto a Ategina: el epígrafe de Bienvenida", Manifestaciones Religiosas en Lusitania. Cáceres, Univ. de Extremadura, 1986, pág. 101.
} 
Callejo Serrano ${ }^{55}$ daba noticia en 1967 de tres aras votivas halladas en las proximidades del Puerto de Las Mezquitas, de las cuales una, con seguridad, estaba dedicada a Nabia. Por su parte, Melena ${ }^{56}$ publica un epígrafe a Nabia procedente de El Gaitán, en plena Sierra de San Pedro. Tenemos así, por tanto, la presencia de una divinidad prerromana relacionada con los manantiales, aunque en otros casos también con los valles, montes y bosques.

Pero, asimismo, se halla representada la divinidad Salus por dos incripciones. Una de ellas se encontró en la finca Los Alijares, del término de Robledillo de Trujillo y está erigida por Marcus lulius Badius (lám. X). La otra lápida, de la que sólo se sabe que procede de los alrededores de Montánchez ${ }^{57}$, está consagrada a Sa (lus) Bidie (n) sis, por lo que Blázquez cree que se refiere al nombre de la fuente, Bidia, de la que era protectora.

No menos significativo es el hecho de que se atestigüe también en esta zona un pozo con el apelativo de Airón. Blázquez ${ }^{58}$, al hablar de las divinidades acuáticas, informa de un altar votivo erigido al dios Airós y encontrado en Fuente Redonda (Uclés, Cuenca). El mismo autor comenta que en otros lugares de la Península se conocen pozos con el mismo nombre de ese "genio de las fuentes", siendo el caso de Montánchez, en nuestra opinión, un buen ejemplo de ello.

Otros interesantes ejemplos se están estudiando en la actualidad en reláción al tema que nos ocupa. Entre los años 1980 y 1983 se llevó a cabo la excavación de un complejo termal romano, situado en el Puerto de la Nava, próximo a la localidad de Cabeza del Buey (Badajoz) ${ }^{59}$. Se han descubierto varias estancias características en estos edificios (hypocaustum, caldarium, frigidarium, piscinas, etc.), además de una importante área de habitación con pavimentos musivos de tipo geométrico.

Estas termas rurales se hallan en íntima relación con las surgencias de aguas ferruginosas y constantes que nutren también a los llamados Baños de Baba, ubicados en su entorno. Dichos baños, de propiedades curativas, se han utilizado hasta mediados de siglo, aunque hoy están en desuso.

${ }^{5}$ Callejo Serrano, C., art. cit., 1967, págs. 87 ss.

${ }^{56}$ MeLENA, J. L., art. cit., 1984.

57 Fita y Colomé, F., "Epigrafia romana de Montánchez...», Bolet. de la R. Acad. de la Hist., XXXVIII, 1901, 407-408.

${ }^{58}$ BLÁzquez, J. M., op. cit., 1977, pág. 307.

${ }^{59}$ Calero, J. A., y Membrillo, I., art. cit., 1982. 


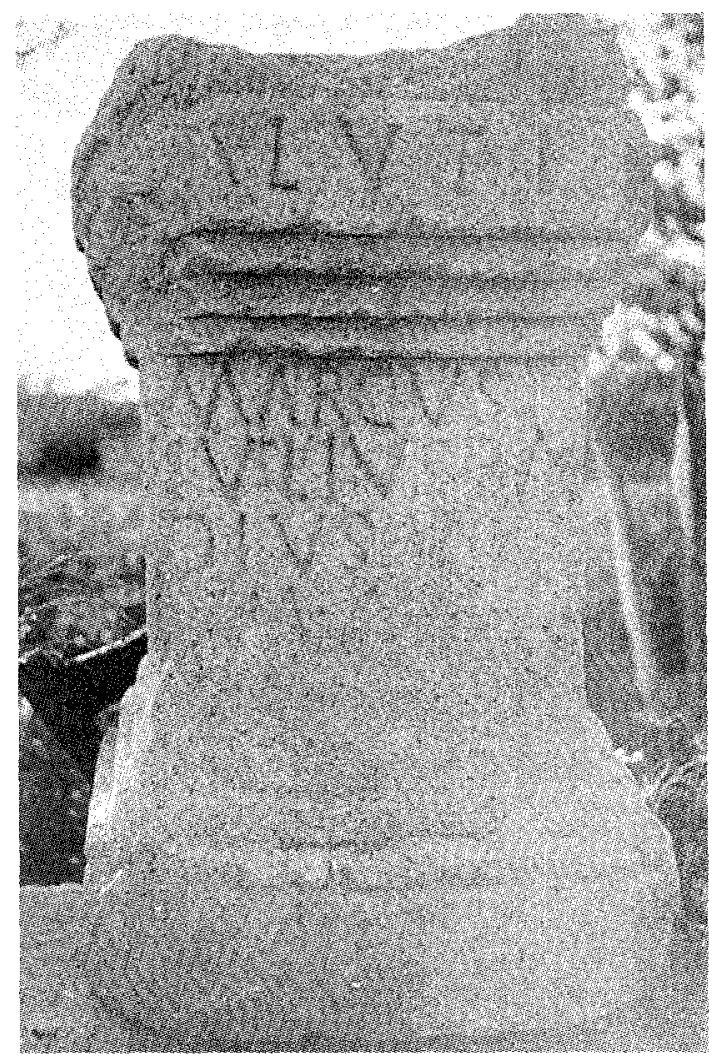

Lám. X. Inscripción votiva a Salus, procedente de la finca “Los Alijares», en Robledillo de Trujillo (Cáceres).

En principio no se conocen testimonios epigráficos de culto a los beneficios de estas aguas. No obstante, cabe tener en cuenta la noticia que da Muñoz Rubio ${ }^{60}$ sobre el hallazgo en este lugar de un torso mutilado de Venus, en mármol blanco y de pobre factura. El autor afirma que esta estatua está considerada como una ninfa de las aguas, y es denominada como la "Venus de Cabeza del Buey».

Otros casos están siendo objeto de una investigación más detallada, por nuestra parte, en el mismo marco de relación entre yacimientos ro-

\footnotetext{
${ }^{60}$ Muñoz Rubio, J., op. cit., 1985, pág. 436.
} 
manos o anteriores y testimonios de culto a las aguas. Elementos de gran interés presenta el enclave llamado Fuente Blanca, en el término de Valencia de Alcántara. Callejo ${ }^{61}$ visitó personalmente el lugar y habla de un santuario romano, ubicado en paraje ameno y en las inmediaciones de una fuente, a la que responde, obviamente, el topónimo. Pasa próximo un tramo de calzada que seria un ramal de la que transcurre entre Norba y Conimbriga.

Se encontraron allí cuatro epígrafes, de los cuales al menos dos tienen relación con los factores salutíferos de dicha fuente. La primera, que corresponde a la número 6 de la publicación de Callejo, está dedicada a Apolo y lleva la fórmula a (nimo) p (osuit) I (ibens). Aunque Apolo es una divinidad romana protectora de las artes en general, sobre todo de la música, se encuentra también en varias inscripciones con el carácter de Apolo medicus ${ }^{62}$. Así, en una lápida de Cortijo de Escaña (Bética) (CIL II 2004) se atestigua en unión con Aesculapius. La asociación de ambas divinidades es documentada en otros casos por Toutain ${ }^{63}$. En Hispania es decisivo el ejemplo del balneario de Caldas de Montbui (Barcelona), donde se han documentado varias dedicaciones a Apolo ${ }^{64}$.

Otra de las inscripciones de Fuente Blanca está consagrada a Salus (núm. 8) y, por tanto, con claras alusiones a factores bienhechores del agua, que ya hemos comentado para esta divinidad.

Por último, estamos ampliando datos, actualmente, para un yacimiento denuminado «El Palacio», del término de Rena (Badajoz), con notables restos arqueológicos romanos, que son extensivos a toda la zona próxi$\mathrm{ma}$, en los alrededores del río Ruecas. Dicha finca ha proporcionado un epigrafe dedicado a Salus, por un individuo libre, L. Tutilius Valentinus ${ }^{65}$. La inscripción vendría dada por los efectos sanadores del agua si, como parece, se encuentra alli un manantial de aguas mineromedicinales.

Finalmente, debemos señalar la importante vinculación de los balnearios con nudos de comunicación y el origen de núcleos urbanos. De este hecho dan pruebas bien patentes en Extremadura los balnearios de Alange y Baños de Montemayor. En Alange las termas fueron el motivo, sin duda, de que se creara un primer núcleo de población intenso, prolon-

61 Callejo Serrano, C., art. cit., 1967, pág. 106.

62 Rodriguez Cortes, J., Sociedad y religión clásica en la Bética romana. Salamanca 1990, pág. 39.

63 Toutaln, J., Les cultes paiens dans l'Empire Romain. París 1967, pág. 65.

${ }^{64}$ Miró, C., Las termas de Caldas de Montbui, en este mismo volumen.

65 GonzÁlEZ CORdero, A., y otros, "Aportaciones a la epigrafía romana en Extremadura", Alcántara, 8. Cáceres 1986, inscrip. núm. 13, con lám. 
gación de Mérida y en la que se implantaron villas de descanso y recreo. Baños de Montemayor ocupa un lugar de privilegio en la calzada romana de la Plata, antiguo camino indigena. En dicha via se constituyó la mansio Caecilius Vicus. En el desarrollo urbano de este enclave fue decisivo el que los romanos utilizaran intensamente sus manantiales de aguas sulfurosas, edificando unas importantes termas.

Ya vimos en otro capítulo de este trabajo cómo muchos balnearios 0 fuentes mineromedicinales se alineaban en la Via de la Plata, al Norte de Cáceres, que en este caso se relacionaba también con un fenómeno geológico. Sin embargo, es evidente la conexión entre los baños o fuentes medicinales romanos y las posibilidades viales o de comunicación, circunstancia que parece confirmarse, asimismo, en el área de Alcántara. En el mismo caso se encuentran las termas de La Nava, en Cabeza del Buey, cercanas a la calzada que se dirige a la zona minera de Almadén, la antigua Sisapo.

\section{CONCLUSIÓN}

Con este trabajo hemos intentado mostrar una panorámica general acerca de las posibilidades de investigación que ofrece la región extremeña respecto al tema de las aguas mineromedicinales. Se constatan aquí varios ejemplos en los que se hace patente la relación entre fuentes o manantiales con caracteres terapéuticos y elementos de culto o sacralización de época romana. Se materializan éstos en testimonios epigráficos, constructivos y toponímicos. Igualmente se evidencia la relación estrecha entre los lugares de aguas mineromedicinales, la distribución de los asentamientos y el trazado de las vías de comunicación. Por último, se atestiguan interesantes casos de pervivencia y continuidad de uso en la cultura cristiana medieval y contemporánea.

Consideramos que futuros estudios aportarán datos cada vez más ricos sobre cada una de estas líneas de investigación que aquí hemos apuntado.

\section{RESUMEN}

Se aborda en este trabajo la situación actual de la investigación referida al tema de las aguas mineromedicinales en la región extremeña. 
La labor de catalogación que hemos llevado a cabo durante cinco años ha dado como resultado el aumento espectacular del número de lugares conocidos, aunque con diferente categorización: Fuente-manantial, Lugar de Baños y Balneario. Contando con esta base de datos, se han establecido relaciones de los lugares con elementos de culto en la antigüedad, documentados a través de la epigrafía, la toponimia y los restos constructivos. Además, se constatan zonas de concentración de lugares, vinculados a razones geológicas, vías de comunicación, densidad de asentamientos, etc.

Asimismo, planteamos un estado de la cuestión que refleja el tratamiento del tema en la bibliografía regional y las líneas de investigación actuales.

\section{ABSTRACT}

This work deals with the present situation of the research in the subject of the mineral and medicinal waters in Extremadura.

The cataloguing task we have carried out for five years, has produced a big increase in the number of known places, bur with different categories: the Spring, the Baths Place and the Spa. Taking into account this database, we have tried to establish the relationship among the place with worship elements, established with documentary evidence through the epigraphy, the toponymy and the building remains. We have observed, moreover, there are some concentration areas of places, which are tied to geological reasons, communication routes and archaeological settlements.

Finally, we propose a viewpoint which shows the treatment of the subject in the regional bibliography and the present outlines of research. 